\title{
Jovens estudantes de direito: notas de pesquisa acerca das expectativas quanto à carreira profissional
}

\author{
Young law students: research notes on professional career expectations
}

Rosane Castilho ${ }^{1}$, Frederico Henrique de Lima e Costa ${ }^{2}$, João Henrique Souza Rocha ${ }^{3}$

\section{RESUMO}

A discussão proposta neste artigo tem por objetivo conhecer as expectativas profissionais dos jovens estudantes do curso de Direito na UEG, Campus Metropolitano, investigar como lidam com os aspectos associados ao mundo do trabalho para além da graduação e identificar a possível existência de um projeto de vida, dos jovens entrevistados, que venha a nortear suas decisões de curto e médio prazos. Os campos da Educação, Psicologia, Sociologia e Direito nortearam a discussão proposta. A pesquisa em tela contou com um instrumento de caráter quanti-qualitativo aplicado virtualmente em uma amostra não probabilística por conveniência que contou com a participação de 86 graduandos. No presente artigo serão apresentados os dados de viés quantitativo associados às expectativas profissionais, já que a referida pesquisa não se encontra finalizada. Os resultados parciais alcançados mostraram um certo receio quanto ao futuro entre os jovens estudantes, não obstante as particularidades da vivência de sua condição juvenil; o reconhecimento de um modelo consistente associado à formação universitária a fim de fazer frente aos desafios da vida profissional e a dúvida quanto à eleição de uma carreira, dadas as inúmeras possibilidades de atuação profissional que envolvem os operadores do Direito.

Palavras-chave: Juventudes. Projeto de vida; Expectativas profissionais; Formação em Direito.

\footnotetext{
ABSTRACT

In increasingly complex work settings, identifying the ways in which the youth plans to face them proves necessary. This exploratory observational study aims to understand the professional expectations of young students at UEG's Law Degree (Metropolitan Campus). Further, it aims to investigate what is their approach to life beyond academic training, identifying life projects that might guide their mid and long-term decision making. Theoretical background in law, psychology, sociology and education guided the rationale of this study and interpretation of results. Quantitative and qualitative instruments were administered virtually to

1 Docente Titular de Psicologia da Universidade Estadual de Goiás. Doutora em Educação, com Estudos Pós-Doutorais em Sociologia da Juventude pela Universidade de Lisboa. Membro do Observatório Juventudes na contemporaneidade (Goiás) e Diretora Adjunta para o Centro-Oeste da REDEJUBRA. Coordenadora da pesquisa. E-mail: rosanecastilho@ueg.br

2 Graduado em Administração pela Universidade Estadual de Goiás, pós-graduando em Gestão de Negócios e monitor da pesquisa. E-mail: fredhenrique30@ outlook.com

${ }^{3}$ Graduado em Publicidade e Propaganda pela Universidade Federal de Goiás. Graduando em Direito pela Universidade Estadual de Goiás e monitor da pesquisa. E-mail:joaohsrocha@ gmail.com
} 
a convenience sample of 86 students. As the research is ongoing, this article will report on professional expectation' data. Partial results indicate that young students are likely to be fearful of the future regardless of the experiences intrinsic to the youth condition. Further, they identified the value of a consistent academic curriculum when facing the challenges of professional life and doubts regarding choice of career, given the countless possibilities of professional performance that involve legal practitioners.

Keywords: Youth, Life Project; Professional expectations; Education in Law.

\section{INTRODUÇÃO}

As pesquisas sobre a temática da juventude crescem em destaque e diferentes áreas da ciência, tais como as ciências humanas e sociais aplicadas, desvelam um notável interesse para investigar diferentes contextos e aspectos que envolvem a condição juvenil no Brasil. Muito já se discutiu, acerca desse tema em outras pesquisas levadas a cabo por essa pesquisadora na instituição (CASTILHO 2017; 2019; 2020) e muitas outras virão porque o que move os pesquisadores é o desejo de conhecer a fundo uma dada realidade.

Importante ressaltar que, no imaginário social, o conceito de juventude ainda se apresenta associado a um processo transitório entre estágios (da infância ou da adolescência até a idade adulta) ou a uma faixa etária específica, embora, como já foi amplamente discutido entre os pesquisadores das ciências humanas e sociais, o conceito de juventude sofreu mudanças, sendo inicialmente compreendido como uma fase de vida particular, em uma tentativa conceitual de unir aspectos de semelhança para caracterizála como homogênea, ignorando a condição de classe, de gênero, de etnia, entre outros aspectos que configuram singularidades na condição juvenil.

Observado esse equívoco, as pesquisas se orientaram no sentido de trazer luz aos aspectos associados à condição juvenil ampliando o espectro para a investigação das características específicas entre grupos de jovens, que podem ser notadas na existência de diferentes culturas juvenis, às (possíveis) contraposições entre os jovens estudantes e os jovens trabalhadores e ainda nas diferenças entre os pertencentes ao contexto urbano e ao rural, permitindo emergir a compreensão de que a juventude, como categoria social, é diversa, construída socialmente a partir de leituras distintas, de acordo com condições sociais, políticas, econômicas e culturais. 
Sob o aspecto jurídico, buscou-se tecer algumas considerações sobre tal tema. De acordo com o art. 227 da Carta Magna brasileira, é atribuído como dever da família, da sociedade e do aparelho estatal assegurar à criança, ao adolescente e ao jovem, com absoluta prioridade, o direito à vida, à saúde, à alimentação, à educação, ao lazer, à profissionalização, à cultura, à dignidade, ao respeito, à liberdade e à convivência familiar e comunitária, além de colocá-los a salvo de qualquer forma de negligência, discriminação, exploração, violência, crueldade e opressão. Já no inciso XV do art. 24, é dada a competência concorrente à União, aos Estados e ao Distrito Federal para legislar sobre a proteção da infância e da juventude.

Nota-se, portanto, o interesse em demonstrar a preocupação do legislador constituinte com o jovem, que com base no inciso I do $\S 8^{\circ}$ do art. 227, preocupação essa que acabou se traduzindo em um estatuto próprio. Sabe-se que a lei 12.852 de 2013, o Estatuto da Juventude, representou "um importante marco para as políticas públicas voltadas ao jovem" sendo fruto de reivindicações de movimentos sociais amplos, dentre eles, os movimentos juvenis (CASTRO E MACEDO, 2019, pág. 1216). Conforme os $\S \S$ $1^{\circ}$ e $2^{\circ}$ do art. $1^{\circ}$ desta lei, as pessoas com idade entre 15 e 29 anos são consideradas jovens, englobando assim uma categoria utilizada no campo da psicologia, os adolescentes, que vem a ser sujeitos com idade entre 15 e 18 anos. Sobre isso, faz-se necessário ressaltar que esses autores (pág. 1224) apontam para a ideia de que o recorte etário segue organismos internacionais, mas é "amplamente criticado" pelo fato de que, ao eleger uma faixa de idade como referência primordial, trabalha por esconder desigualdades sociais presentes, especialmente, em países em desenvolvimento.

O conceito de juventude - tendo por referência a psicologia como campo de conhecimento - ainda se apresenta associado a um processo transitório entre estágios (infância, adolescência, adultez) ou a uma faixa etária que compreende um recorte específico, embora, como já foi amplamente discutido entre os pesquisadores das ciências humanas e sociais, o conceito de juventude, inicialmente compreendido como uma fase da vida - em uma tentativa conceitual de unir aspectos de semelhança para caracterizá-la como homogênea - falhou ao não considerar aspectos relevantes tais como condição de classe, gênero, etnia, entre outros que configuram singularidades na condição juvenil.

Observado esse equívoco, as pesquisas se orientaram para a investigação das características específicas entre grupos de jovens, que podem ser notadas na existência de 
diferentes culturas juvenis, nas contraposições entre características que envolvem jovens trabalhadores que estudam e ainda nas diferenças entre os jovens pertencentes ao contexto urbano ou ao rural. Esse olhar permitiu o emergir da compreensão de que a juventude, como categoria social, é diversa e construída socialmente a partir de leituras distintas "de acordo com condições sociais, políticas, econômicas e culturais" (DOUTOR, 2016, pág. $161)$.

Pelo viés sociológico da temática em questão, é interessante a classificação entre diferentes abordagens da juventude sustentada por Groppo (2017). Sob essa abordagem, a concepção de juventude pode ser interpretada pelos modelos estrutural-funcionalista, crítico e pós-crítico. A primeira estabelece que os jovens têm a necessidade de se adaptar a uma estrutura social vigente, obedecendo suas regras e valores, sendo a vida adulta configurada pelo ingresso da pessoa no mercado de trabalho e pela constituição de domicílio próprio; já na vertente crítica, a condição de classe e o ciclo vital são valorizados, sofrendo a transição para a vida adulta influência de variáveis, como o gênero, a etnia, a condição urbano-rural e a religião. A terceira vertente, denominada póscrítica, tem como proposta pensar a juventude como um modo de ser, um estilo de vida, tentando compreender essa categoria social "cujo protagonismo vai na direção das sociabilidades emergentes" a partir de valores e símbolos que a dão a ela representatividade (CASTILHO, 2019, pág. 22) e cuja 'verdade' demanda aspectos singulares, a partir dos quais "as forças disciplinares são relativizadas".

Retomando a proposta da pesquisa, ao buscar compreender as expectativas dos jovens estudantes quanto a uma carreira identificada como "de elite", o que nos move é também buscar descobrir, como nos orientou Foucault $(2018,2021)$ acerca da potência dos "regimes de verdade" instituídos socialmente, se a busca por uma formação acadêmica na área jurídica encobre uma busca por valoração social pela via da atuação profissional.

Neste sentido, se "a verdade" se mostra através do discurso científico, as instituições que a produzem, atuam no sentido de disseminar e sugerir, via discurso, comportamentos e valores, sancionados pela vida de técnicas e procedimentos. Assim, nos cabe aqui indagar ainda sobre a magnitude da subjetividade individual nas escolhas profissionais em determinadas carreiras. 


\section{Notas sobre a formação jurídica no Brasil}

É de consenso entre pesquisadores do campo jurídico que a independência do Brasil foi fundamental para o estudo jurídico, já que Portugal não autorizava a fundação de faculdades de Direito em sua colônia sul-americana. Com isso, elas surgiram primeiramente nos estados de Pernambuco e de São Paulo. Nesse período, como apontado por Rubião (2017, pág. 96), foi criada uma "cultura do bacharelismo", com a intenção de formar jovens no ensino superior para que pudessem alcançar "cargos de importância na sociedade" e assim fazer emergir uma "elite dirigente". Esse projeto teve como destaque o curso universitário de Direito a fim de atender ainda a um contexto que demandava uma formação consistente a funcionários da administração pública e profissionais liberais.

Além de aspectos tais como a tradição e o imaginário social elitista, a variedade de possibilidades de escolhas profissionais que o bacharel em Direito possui, de acordo com alguns autores, permitiu eleger esse curso como o "porto seguro das Ciências Humanas" (RUBIÃO, 2017, pág. 97).Uma certa cultura elitista, conforme o mesmo autor, ainda permanece no imaginário das faculdades de Direito no Brasil, não obstante o fato de que o ingresso em cursos universitários mostrar-se mais acessível aos candidatos ao curso superior em Direito.

Ainda sobre o caráter de elitismo, faz-se importante citar a Teoria das Elites, segundo a qual em todas as sociedades, sempre existiu um grupo detentor do poder, mesmo que minoritário em número de pessoas, em contraposição a outro grupo, destituído de poder simbólico. Essa contenda parece desvelar uma incapacidade social de "transcender/ultrapassar os interesses das elites" que a sustentam, valorizando posturas atreladas ao personalismo, ao individualismo e à lógica da acumulação (NUNES, 2020, pág. 88).

Alguns autores apontam para o pressuposto de que o que o caráter elitista do curso de Direito (e da própria ciência) seduzem muitos estudantes, o que alimenta a grande expansão dos referidos cursos em todo o território nacional. Retomando Nunes (pág. 90), o curso de Direito tem sido objeto de desejo das elites, já que a pouco mais de cem anos, "a maior parte dos seres humanos que aqui viviam não era sequer considerada humana pelas elites". Assim, o fato de existirem políticas afirmativas para os indígenas, segundo o autor, confirma o dado de que um século não foi suficiente para que os modos e meios de acesso aos cursos universitários considerados "de elite" fossem ampliados. 
Essa é uma questão que precisa ser observada tendo em vista a escolha da carreira em tempos incertos. Para além disso, o "princípio de regularidade" dos discursos institucionais (FOUCAULT, 2011, pág. 53), que encaminha para a percepção de uma "face legível" da realidade que deveria ser percebida e aceita como verdade, demandam a todo o tempo a adesão irrestrita aos seus pressupostos. Neste sentido, a escolha de um curso universitário socialmente reconhecido nos parece um caminho para compreender a magnitude dos números que envolvem os candidatos à carreira jurídica no país.

\section{Expectativas profissionais: especificidades na carreira dos Profissionais do Direito}

Na construção de um projeto de carreira, a transição do ensino médio para o ensino superior assume uma importância na vida profissional, pois o indivíduo "escolhe a carreira" à qual quer seguir durante a sua vida, mesmo que tal escolha seja de forma prematura, dada uma visão parcial do mundo de trabalho, sustentada, em grande parte, pelos discursos acerca do valor/desvalor social de determinadas carreiras. Na transição da universidade para o mundo de trabalho, ocorre ainda, segundo pesquisadores do campo das ciências humanas, uma crise de identidade a partir da qual os sujeitos passam a rever suas potenciais escolhas, avaliando se estão em consonância com seus modos de vida e ainda com suas aspirações pessoais.

Sob um ângulo mais pragmático, o "mercado de trabalho para o curso de Direito", apresenta uma situação especial, ou como os próprios juristas gostam de expressar, uma situação sui generis: o bacharel em Direito se vê diante de muitas opções de carreira, sendo as principais as de advogado (caso tenha aprovação no exame da OAB) e os concursos públicos específicos tais como magistratura, promotoria, procuradoria, advocacia pública, dentre outros.

Outra aspiração apontada é a de professor universitário, tendo em vista o grande número de cursos de graduação em Direito - segundo levantamento feito pelo Inep em 2019, são 1.569 no Brasil, sendo 1.390 em instituições de ensino superior privadas -. Sobre o quantitativo de advogados, que na data dessa pesquisa apontava o número de 1.210.227 profissionais, conforme previsto no site da Organização dos Advogados do Brasil, há que se comentar que pesquisas apontam para um desencantamento quanto à atuação profissional na carreira, tal como nos informa Freitas (2017) ao buscar desvelar 
a trajetória, os projetos de carreira e as expectativas de sucesso de concluintes do ensino superior que autodeclaram não pretender atuar na área de formação.

Acerca da normativa para o exercício da profissão, faz-se necessário comentar que o registro na Ordem é requisito para os bacharéis poderem atuar na advocacia privada no território nacional sendo a prova realizada (comumente) três vezes ao ano, em duas distintas etapas. A primeira é de múltipla escolha, devendo o candidato acertar ao menos $50 \%$ de 80 questões. Já a segunda é composta por quatro questões discursivas e a ainda a redação de uma peça jurídica. Caso o estudante seja reprovado nesta última etapa, poderá, na próxima tentativa, participar diretamente na segunda fase. Após ser aprovado no exame, o profissional poderá estabelecer-se em um escritório de advocacia, na condição de sócio ou contratado como empregado celetista ou associado, tendo estes últimos a ausência de alguns benefícios da Consolidação das Leis do Trabalho. Pereira (2019, pág. 47) aponta para uma realidade hostil na qual formas de trabalho irregulares são comumente criadas, com salários e condições de trabalho relativamente inferiores, em especial para os novos advogados, considerados inexperientes no exercício da atividades jurídicas.

Já nas carreiras públicas, existem concursos, nos três Poderes, que somente os que possuem formação completa em Direito podem se candidatar e alguns concursos que, por sua especificidade, exigem também o registro na OAB. Segundo Pereira (2019, pág. 48), fatores como a estabilidade, os altos salários, o menor nível de estresse, o respeito social e a desvalorização da advocacia privada têm seduzido cada vez mais os denominados “concurseiros" graduados em Direito. Outra situação apontada pelo mesmo autor (pág. 52) é a procura por concursos que exigem apenas o ensino médio, tendo em vista a desvalorização da posição de advogado associado, situação comum aos recém-formados.

Nesse diapasão, não obstante a ideia fortemente disseminada de que "o mundo passou por várias transformações econômicas e sociais nas últimas décadas, tornando o mercado de trabalho cada vez mais numeroso e competitivo", há que se pensar acerca dos inúmeros "ruídos" no que concerne à escolha de uma atividade profissional que demandará qualificação e grandes esforços de ordem pessoal. Acerca das percepções associadas à vida acadêmica, dos aspectos que envolvem os Projeto de Vida e das expectativas quanto ao futuro, discorreremos a seguir. 


\section{METODOLOGIA}

A pesquisa exploratória, de caráter quanti-qualitativo contou com uma amostra do tipo não probabilística por conveniência - onde a seleção dos participantes atendeu a um perfil pré-estabelecido pelo pesquisador - foi composta por um universo de 86 (oitenta e seis) jovens universitários do curso de Direito, sendo 26 (vinte e seis) participantes provenientes do segundo período do curso universitário, 23 (vinte e três) provenientes do terceiro período e 37 (trinta e sete) participantes provenientes do quinto período, perfazendo um total de $80,37 \%$ dos alunos regularmente matriculados e frequentando o semestre letivo.

Como critério de exclusão da pesquisa, definiu-se que os acadêmicos que não se enquadrassem no quesito "idade entre 18 e 29 anos" estariam inaptos a participar da pesquisa, levando em consideração a proposição do art. $1^{\circ}$ do Estatuto da Juventude (Lei $\mathrm{n}^{\mathrm{o}} 12.852$, de 5 de agosto de 2013) que nos orienta quanto à faixa etária como aspecto norteador inicial.

Para a coleta de dados, foi aplicado um instrumento composto por três blocos contendo um total de 24 (vinte e quatro) questões fechadas de cunho objetivo, e 7 (sete) questões abertas, a fim de alcançar melhor compreensão dos dados apresentados. A referida pesquisa foi aprovada no Comitê de Ética em Pesquisa da Universidade Estadual de Goiás, com parecer nº 4971344.

A aplicação do instrumento aconteceu no mês de março do ano de 2021. O envio do questionário digital foi realizado a partir da disponibilização do link via rede social whatsapp aos alunos devidamente matriculados no curso de Direito, no referido mês. Optou-se por aplicar o questionário entre os estudantes do segundo, terceiro e quinto períodos, a fim de identificar a existência e compreender possíveis mudanças dos aspectos fundantes da construção de um projeto de vida de jovens estudantes do Curso de Direito - Campus Metropolitano, em distintos momentos da vida acadêmica. Buscou-se ainda compreender como é constituída a subjetividade juvenil no que tange às particularidades dos respondentes associadas às representações de futuro, suas expectativas profissionais e ainda os obstáculos vivenciados no contexto de formação acadêmica. No presente artigo, serão analisados os dados referentes ao terceiro bloco do instrumento de coleta de 
dados, associados ao Projeto de Vida e às Expectativas profissionais dos acadêmicos. Reiteramos que a presente pesquisa não se encontra concluída em sua totalidade, demandando ainda a análise das questões subjetivas e, ainda, a triangulação dos dados coletados.

Importante ressaltar que o anonimato dos participantes foi considerado um dos fatores fundamentais da pesquisa, assim, os jovens universitários foram informados de que, caso se sentissem constrangidos tanto no que diz respeito ao conteúdo das respostas, quanto no que se refere à sua participação, poderiam recusar-se a participar em qualquer etapa da pesquisa. Nesse escopo, as principais dificuldades encontradas na pesquisa referem-se, principalmente, à aplicação dos instrumentos em meio digital, já que nem todas as questões foram respondidas em sua integralidade. Sensibilizar os jovens acadêmicos quanto à participação na pesquisa também demandou reuniões, buscando parcerias com representantes do Centro Acadêmico do curso, de docentes bem como do coordenador do curso de Direito da instituição.

\section{RESULTADOS E DISCUSSÃO}

Para que não restem dúvidas, é importante esclarecer que os dados aqui apresentados seguem um princípio: foram explorados apenas aqueles que não guardarem estreita relação com as questões subjetivas, que, conforme informado inicialmente, ainda se encontram em processo de análise. Informe realizado, prosseguimos.

O primeiro bloco de questões da pesquisa envolve dados envolve 6 (seis) questões acerca de sexo; idade; religião trabalho e salário (caso o respondente informe que trabalha). Todos os dados desse bloco serão apresentados aqui. Quanto à variável 'sexo', a maior parte da amostra se autodenominou pertencente ao sexo feminino 51,2\% enquanto que os jovens que se autodenominaram do sexo masculino contaram 48,8\%. A alternativa "prefiro não responder" não obteve adesão. Cabe ressaltar que esses dados correspondem apenas à faixa etária delimitada na pesquisa: estudantes com idade entre 18 e 29 anos. Quanto à variável 'idade', 70,9\% da amostra declararam compor a faixa entre 18 e 21 anos, $15,1 \%$ declararam pertencer à faixa entre 26 e 29 anos e 14\% declararam compor a faixa entre 22 e 25 anos. 
Ainda no primeiro bloco, quanto ao tema 'religião', 72,1\% dos respondentes declararam que sim; 25,6\% declararam que não e 2,3\% preferiram não declarar. Entre as denominações mais citadas estão evangélicos e católicos. No que concerne ao quesito 'trabalho', 39,5\% dos respondentes informaram trabalhar em outra área de atuação e 24\% informaram estar empregados em funções que envolvem a área jurídica. Dos respondentes, $7 \%$ informaram não trabalhar. O percentual restante envolve respondentes que estão buscando emprego e ainda aqueles que informam estar desempregados. Dos respondentes empregados, 74,4\% informaram receber até 1 (um) salário mínimo; 19,8\% informaram receber entre 2 (dois) e 3 (três) salários mínimos e 5,8\% informaram receber acima de 3 (três) salários.

Acerca da precarização do trabalho associada à condição juvenil, Pais (2005) sustenta que, na luta diária, o trabalho é um elemento primordial, dados os "anseios insistentes de independência". Nesse sentido, 'suportar' um trabalho com baixa remuneração pode representar a desesperança, já que, de acordo com Castel (1998), o processo de reestruturação produtiva tem provocado alterações significativas nas relações de trabalho, incidindo em fatores como a precariedade laboral e o desemprego

O segundo bloco do instrumento de coleta de dados contou com 8 (oito) questões, das quais iremos, aqui, explorar 4 (quatro) delas. Quanto à adequação da matriz curricular do curso de Direito e as exigências do mundo do trabalho, 46,5\% dos respondentes informaram que sim; 38,4\% responderam que consideram a matriz parcialmente adequada; 5,8\% responderam que não e 9,3\% informaram não saber responder. Perguntados se consideram que a formação universitária oferece os recursos suficientes para a empregabilidade, $52,3 \%$ responderam que sim; $8,1 \%$ responderam que não e 39,5\% informaram considerar 'parcialmente'. Quando indagados se consideram que os saberes adquiridos na universidade são importantes na construção do Projeto de vida, 94,2\% dos respondentes informaram que sim. Os dados coletados nos levam a considerar a importância da formação superior no imaginário social, levando, inclusive, a um superdimensionamento dos capitais possivelmente alcançados com um diploma de ensino superior.

Acerca de uma certa 'idealização' da formação superior, Schwartzman, Filho e Coelho (2021, pág. 181) sustentam ser necessário adotar um sistema avaliação das instituições de educação superior que permita tornar transparente à sociedade, aos agentes 
públicos e às instituições em geral, os seus objetivos institucionais, seus nichos mercadológicos e suas vantagens competitivas a fim de permitir, entre outras possibilidades, que os estudantes "ao entrar em uma instituição de ensino superior, saibam o que esperar, além do simples diploma". Esse sistema poderia ainda, segundo os autores, subsidiar políticas orientadas para a garantia da qualidade e da equidade da educação superior em distintos níveis e dimensões. Em nosso entendimento, o modelo proposto, pela via de sua provável eficácia técnico-administrativa, garantiria a manutenção dos "regimes de verdade" associados à educação superior, tendo nas instituições de ensino, nos órgãos e agências de fomento, a sua base de sustentação.

O terceiro e último bloco que compõe o instrumento de coleta de dados dispõe de 10 (dez) questões objetivas, dentre as quais iremos explorar 6 (seis) delas. Quanto à questão associada à existência de um Projeto de Vida pessoal, 48,8\% responderam afirmativamente, o mesmo percentual respondeu que pensa a respeito, porém não dispõe de um projeto de vida já definido e $2,4 \%$ responderam nunca pensaram a respeito (quando da segunda fase da análise dos dados, buscaremos associar as respostas relativas às expectativas profissionais, entre os estudantes que informaram dispor de um projeto de vida, a fim de identificar se esses respondentes informaram expectativas mais otimistas quanto ao futuro ou se não houve correlação entre esses dados específicos). Quando indagados sobre a área prioritária da vida, a curto prazo, 87,2\% informaram a área profissional. Quando perguntados sobre os maiores aliados na realização de seu Projeto de Vida, a família contou com $46,5 \%$ das respostas informadas e a universidade com $27,9 \%$. Essas duas instituições figuraram entre as mais citadas.

Quanto à questão que envolve o desejo de 'formar uma família nos próximos cinco anos', 44,2\% dos respondentes responderam afirmativamente, 43\% dos respondentes informou não ter esse desejo em curto prazo (na segunda fase da análise buscaremos associar esse dado à condição de gênero) e 12,8\% informaram dúvida quanto ao tema. Ao pensar em 'Futuro', as palavras que os respondentes elegeram como mais significativa foram: Sucesso, bem-estar, realização, estabilidade e dinheiro. Neste sentido, Ribeiro (2009) propõe refletir sobre a trajetória profissional como um constructo teórico-prático, pelo viés dos saberes associados à Psicologia Social e do Trabalho, a fim de analisar as principais formas de compreensão e estruturação da carreira, desvelando uma postura 
crítica quanto à proposta costumeira de eleger os aspectos econômico-financeiros como preponderantes quando da escolha profissional.

Quando indagados sobre os aspectos que envolvem o trabalho ideal, os dois quesitos mais citados foram 'realização pessoal' que contou com 90,7\% das respostas, 'estabilidade' que contou com 73,3\% e 'remuneração' com 68,6\% das respostas informadas. Importante citar que, nessa questão, os respondentes poderiam eleger mais de um aspecto. 47,7\% dos respondentes informaram que o 'significado social' da profissão é um aspecto relevante. Acerca disso podemos associar o peso das convenções sociais cujos valores, reproduzidos nos discursos cotidianos, traduzem uma "reflexividade impositiva", discussão na qual Pais (2010) muito contribui ao nos convocar a avaliar a efetividade do uso indiscriminado dos modelos orientados pelo passado em nossas decisões cotidianas.

\section{CONSIDERAÇÕES FINAIS}

Não obstante o fato de que a pesquisa não se encontra finalizada, tendo apenas os dados quantitativos tratados e parcialmente analisados - já que a triangulação entre os mesmos está programada para a segunda fase -, cumpre informar que, ao buscar conhecer as expectativas profissionais dos jovens estudantes do curso de Direito na UEG, Campus Metropolitano, investigar como lidam com os aspectos associados ao mundo do trabalho para além da graduação e identificar a possível existência de um projeto de vida, dos jovens entrevistados, que venha a nortear suas decisões, verificou-se que um percentual considerável de jovens estudantes do referido curso considera a formação acadêmica como parte fundamental na construção de seu Projeto de Vida, associado, a priori, a formação superior a melhores condições de vida e ascensão social.

Cabe aqui atentar para questões como a "escolha" de um curso considerado "de elite" também compõe o imaginário dos jovens estudantes, no sentido da incorporação de valores sociais externos a si. No que se refere às estratégias de enfrentamento dos desafios acadêmicos figuram predominantemente aquelas que envolvem conciliar a carga de trabalho e disciplina de estudos a fim de alcançar uma formação mais sólida, já que quase a totalidade dos respondentes informa que os saberes adquiridos no curso de graduação são importante ferramenta na consecução de seus objetivos de ordem profissional. 
No que tange ao Projeto de vida, embora parte dos jovens estudantes informe já ter pensado no assunto mas não ter um planejamento definido em mente, os respondentes, em sua maioria, informam que sua área prioritária é a carreira profissional e para levar a cabo seus objetivos, informam pretender se qualificar para além do curso de graduação, o que parece sustentar o discurso corrente de que qualificação acadêmica e melhores padrões de empregabilidade se associam. No que se refere aos maiores obstáculos na consecução do seu projeto de vida, o mercado de trabalho altamente competitivo e as políticas governamentais foram os mais citados.

No que concerne aos receios quanto ao futuro, os mais citados foram o de não conseguirem superar os obstáculos no mundo do trabalho e o receio de não serem capazes de dar andamento à carreira escolhida. Essas respostas vão ao encontro de pesquisas acadêmicas realizadas em distintos cursos associados à formação de profissionais liberais, quais sejam, aqueles que podem trabalhar por conta própria, sem vínculo empregatício e sem a necessidade de registros profissionais, demandando apenas o registro em uma ordem ou conselho profissional. Outro aspecto a considerar é o da limitação associada ao valor dos "sonhados diplomas universitários" em cenários de flexibilização e precarização laboral.

No que se refere às expectativas profissionais, os jovens estudantes oscilam entre as diversas possibilidades de atuar na carreira jurídica e o receio de que o cenário políticoeconômico não favoreça a realização daquilo que alguns chamam de sonho e outros de desejo. A busca por ascensão social e econômica também figura entre os resultados da pesquisa, tendo sido discutida aqui a partir dos paradigmas sociais vigentes, amplamente disseminados e adotados como verdade e que envolvem, dentre outros aspectos, a demanda por sucesso e enriquecimento.

Necessário expor as principais dificuldades encontradas na realização da pesquisa envolveram a aplicação do instrumento na modalidade virtual, em função da pandemia Covid19. As orientações para procedimentos em pesquisa em ambiente virtual, disponibilizadas via ofício circular da Secretaria Executiva do Conselho Nacional de Saúde- Ministério da Saúde, foram fundamentais, tanto no que tange aos procedimentos que envolvem contato através de meio virtual, quanto no que concerne à segurança na transferência e no armazenamento de dados, porém, nada pode substituir o contato presencial com os respondentes. Para além disso, espera-se que as instituições de ensino 
superior e os órgãos de fomento subsidiem condições de trabalho aos pesquisadores a fim de enriquecer as discussões acerca dessa e de outras temáticas tão caras às ciências humanas e sociais.

\section{REFERENCIAS}

BRASIL. Constituição (1988). Constituição da República Federativa do Brasil. Brasília, DF: Centro Gráfico, 1988.

BRASIL. Lei no 8.069, de 13 de julho de 1990. Dispõe sobre o Estatuto da Criança e Adolescente e dá outras providências. Diário Oficial da União, Brasília, DF, v. 04, n. 135, 16 de julho de 1990.

CASTILHO, R. Juventudes: pesquisa e produção de conhecimento. Goiânia: Espaço Acadêmico, 2017.

2019.

Cartografias da condição juvenil. Goiânia: Cânone Editorial,

CASTILHO, R. \& NEDEL, V. Juventudes Latino-Americanas. Jundiaí: Paco Editorial, 2020.

CASTRO, E. G.; MACEDO, S. C. Estatuto da Criança e Adolescente e Estatuto da Juventude: interfaces, complementariedade, desafios e diferenças. Revista Direito e Práxis, Rio de Janeiro, v. 10, n. 2, p. 1214-1238, 2019.

CASTEL, R. As metamorfoses da questão social: uma crônica do salário. Petrópolis: Vozes, 1998.

DOUTOR, C. Um olhar sociológico sobre os conceitos de juventude e de práticas culturais: perspectivas e reflexões. Última década, no 45 , Proyecto Juventud, p. 159174, 2016.

FOUCAULT, M. A ordem do discurso. São Paulo: Edições Loyola, 2011.

Do governo dos vivos. São Paulo: Martins Fontes, 2018.

Microfísica do poder. São Paulo: Paz e Terra, 2021.

FREITAS, O. A. Trajetória, projetos e expectativas de sucesso na carreira: estudo com universitários concluintes que não pretendem atuar na área de formação. Revista

Brasileira de Ensino Superior, Passo Fundo, vol. 3, n. 2, Abr.-Jun, p. 58-78, 2017. GROPPO, L. A. Introdução à Sociologia da Juventude. Jundiaí: Paco Editorial, 2017.

INSTITUTO NACIONAL DE ESTUDOS E PESQUISAS EDUCACIONAIS ANÍSIO TEIXEIRA. Sinopse Estatística da Educação Superior 2019. Brasília: Inep, 2020. Disponível em: http://inep.gov.br/sinopses-estatisticas-da-educacao-superior. 
NUNES, J. Caminhos para democratização do Direito. Salvador: Juspodivm, 2020.

PAIS, J. M. Ganchos, tachos e biscates: jovens, trabalho e futuro. Porto: Ambar, 2005.

Lufa-lufa quotidiana: ensaios sobre cidade, cultura e vida urbana. Lisboa: Imprensa de Ciências Sociais, 2010.

PEREIRA, R. B. Expansão universitária e mercado de trabalho: consequências no campo do direito. Cadernos de Pesquisa, São Paulo, v. 49, n. 171, abr./jun, p. 34-58, 2019. Disponível em: https://doi.org/10.1590/198053145788.

RUBIÃO, A. Ser estudante de Direito no século XXI. Direitos Culturais: Santo Ângelo, v.12, n.26, p. 91-108, jan./abr, 2017.

RIBEIRO, M. A. A trajetória da carreira como construção teórico-prática e a proposta dialética da carreira psicossocial. Cadernos de Psicologia Social do Trabalho, v. 12, n. 2, p. 203-216, 2009.

SCHWARTZMAN, S.; FILHO, R. L. S. e COELHO, R. Por uma tipologia do ensino superior brasileiro. Estudos Avançados, v. 35 n. 101, p.153-188, 2021. Disponível em: https://doi.org/10.1590/s0103-4014.2021.35101.011. 